\title{
'Low Cost' Three Phase to Single Phase Matrix Converter
}

\author{
Malcolm Tabone, Cyril Spiteri Staines, Joseph Cilia \\ University of Malta, Faculty of Engineering, Msida. MSD06, Malta. \\ FAX: +35621343 577, TEL: +35621333995 , URL: http://www.eng.um.edu.mt \\ Email: cispit@eng.um.edu.mt, jcilia@eng.um.edu.mt
}

\begin{abstract}
This paper presents the design and implementation of a single leg matrix converter. It shows the basic operation of this type of converter, the modulation used and its implementation on a-low cost microcontroller. Four-step current commutation is used for switching between two bi-directional switches. The final system is implemented to control the speed of a single-phase induction motor.
\end{abstract}

\section{INTRODUCTION}

In recent years, the hard switching three-phase to threephase matrix converter (MC) has received considerable attention as an alternative to the dc-voltage-link converter with active front-end. Numerous publications have dealt with modulation schemes [1]-[3], operation at unbalanced input voltages [4], [5], semiconductor device and packaging technology [6], [7], gate drive concepts [8], and the commutation procedure for bi-directional switches (BDSs) [9]. MC technology has matured and is considered for a variety of industrial applications where a substantial amount of energy can be fed back to the mains, such as in rolling mills, conveyor belts, and elevators. The attractiveness of $\mathrm{MC}$ technology is increasing due to several factors, including the rapid decline in semiconductor costs, the advent of novel packaging concepts, and improvements in both on state and switching characteristics of the semiconductors. For example, an insulated gate bipolar transistor (IGBT) module containing nine forward and reverse blocking BDSs using state-of-the-art trench gate technology was presented in [7].

The trend in electrical drives is to integrate the frequency converter, the electrical motor, and even the gear or the pump into a single unit, in order to reduce the costs and thus to increase the overall efficiency and the equipment reliability.
Nowadays, adjustable speed drives (ASDs) constitute a well established technology. Due to the high switching frequencies ( 5 to $20 \mathrm{kHz}$ ) of the insulated gate bipolar transistors (IGBTs), ASDs are capable of producing highresolution waveforms which minimise motor losses caused by the current harmonics. Also, due to the low losses of the IGBTs, the frequency converter can reach efficiencies of 0.98 p.u. at full load. Furthermore, smart strategies to drive the motor, such as flux optimization, are able to increase the overall efficiency of the electric drive even further [10]-[12].

Among the most desirable features in power frequency changers are the following:

1. Simple and compact power circuit;

2. Generation of load voltage with arbitrary amplitude and frequency;

3. Sinusoidal input and output currents;

4. Operation with unity power factor for any load;

5. Regeneration capability.

Matrix converters can fulfill these ideal characteristics, and this is the reason for the tremendous interest in the topology.

The matrix converter is a forced commutated converter, which uses an array of controlled bidirectional switches as the main power elements to create a variable output voltage system with unrestricted frequency. It does not have any dc-link circuit and does not need any large energy storage elements.

However, the MC technology has some drawbacks. Some of these are:

1. High component count

2. Lower than unity voltage transfer ratio

3. Sensitive to disturbances

4. Current commutation 
Some of these drawbacks can be eliminated and some can be reduced by either some additional hardware or by optimization of the software.

\section{THEORY}

In this section we will consider a three-phase to singlephase matrix converter. Each output line can be connected to the three inputs by means of the three switches $S_{1}, S_{2}$, $S_{3}$. The three switches are closed sequentially, at a fixed switching period. During the $\mathrm{k}^{\text {th }}$ switching sequence, let the times along which the switches $S_{1}, S_{2}, S_{3}$ are closed be denoted by $t_{1}^{k}, t_{2}^{k}, t_{3}^{k}$, where :

$t_{1}^{k}+\mathrm{t}_{2}^{\mathrm{k}}+\mathrm{t}_{3}^{\mathrm{k}}=\mathrm{T}_{\mathrm{seq}}=\frac{1}{f_{s e q}}$

and where $T_{\text {seq }}$ is a constant. The lengths of, $t_{1}{ }^{k}, t_{2}{ }^{k}, t_{3}{ }^{k}$ determine the converter operation. A constraint can be expressed by

$S_{1}+S_{2}+S_{3}=1$

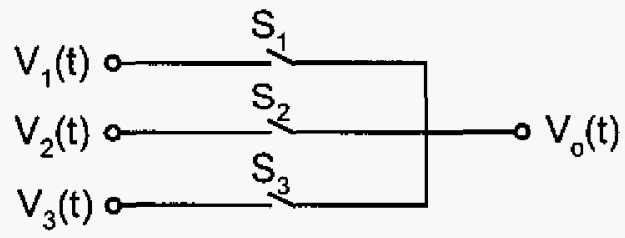

Figure 2.1: Three-phase input, single-phase output converter structure.

The output voltage waveform $V_{0}$ is a discontinuous function, which consists of chopping of the three input voltages, assembled sequentialiy. In general, the output voltage Fourier Spectrum depends on input voltage, frequency, and on the converter switching law.

During the $\mathrm{k}^{\mathrm{th}}$ sequence, the average output voltage can be approximated by

$V o_{a v}^{k}=V_{1} t_{1}^{k}+V_{2} t_{2}^{k}+V_{3} t_{3}^{k}$

where $V_{1}, V_{2}, V_{3}$ are the input phase voltages, measured at the same time during the $k^{\text {th }}$ sequence, and considered constant.

The output sequence average $V \boldsymbol{o}_{\alpha \nu}{ }^{k}$ in eq.3 can be determined by summing three vectors, representing the input voltages, rotating at angular frequency $\omega_{i}$, weighted by the switching times $t_{1}{ }^{k}, t_{2}{ }^{k}, t_{3}{ }^{k}$ (Fig. 2.2).
If for all $\mathbf{k}, t_{l}{ }^{k}=t_{2}{ }^{k}=t_{3}{ }^{k}$, then the average output voltage is zero.

If, for all $\mathrm{k}, t_{1}^{k}, t_{2}^{k}, t_{3}^{k}$ are constant, then the resulting output vector is fixed with respect to the input vectors. Therefore, the output voltage is sinusoidal, at the input frequency. Its amplitude and phase can be adjusted by varying $t_{3}, t_{2}, t_{3}$.

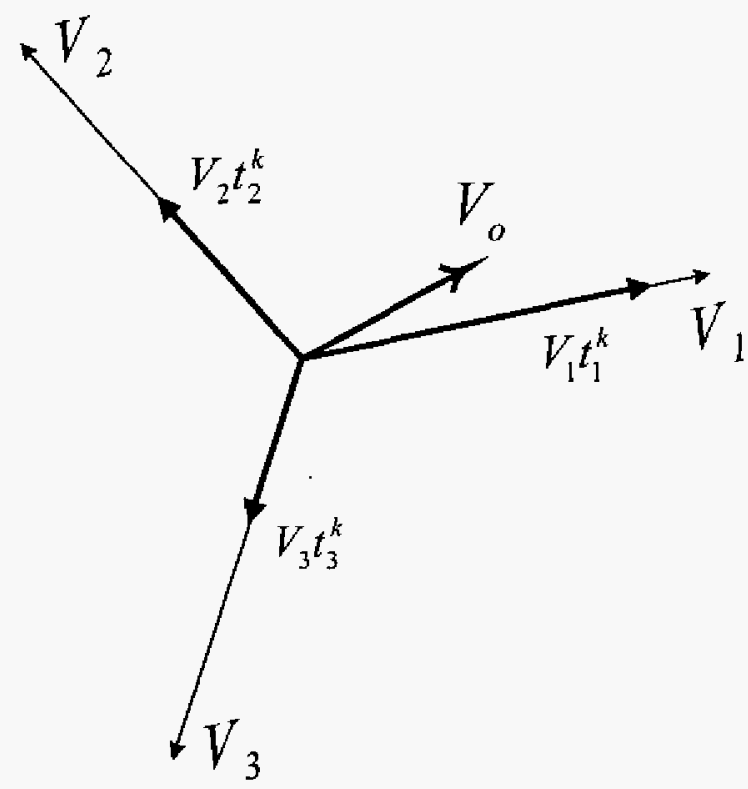

Figure 2.2: Output voltage synthesis.

Finally, if

$$
\begin{aligned}
t_{1}{ }^{k} & =\frac{T_{\text {seq }}}{3}\left[1+2 q \cos \left(K T_{\text {seq }} \omega_{m}\right)\right] \\
t_{2}{ }^{*} & =\frac{T_{\text {seq }}}{3}\left[1+2 q \cos \left(K T_{\text {seq }} \omega_{m}-\frac{2 \pi}{3}\right)\right] \\
t_{3}{ }^{*} & =\frac{T_{\text {seq }}}{3}\left[1+2 q \cos \left(K T_{\text {seq }} \omega_{m}-\frac{4 \pi}{3}\right)\right]
\end{aligned}
$$

the resulting vector $V o$ has constant amplitude $q V_{i m}$, and rotates with respect to the input vectors, with angular frequency $\omega_{m}$. Therefore, the output voltage is sinusoidal, characterized by amplitude $q V_{i m}$ and angular frequency $\omega_{v}=\omega_{i}+\omega_{m}$ 


\section{A. Yoltage ratio limitation}

For a $\mathrm{MC}$, used to convert from a three phase to a single phase with neutral system, the modulation solutions in (4) have a maximum voltage ratio $(q)$ of $50 \%$ as illustrated in Fig. 2.3. The output voltage can be further increased to $86.6 \%$, however the output waveform will be distorted and will contain other harmonies other than that required from the output.

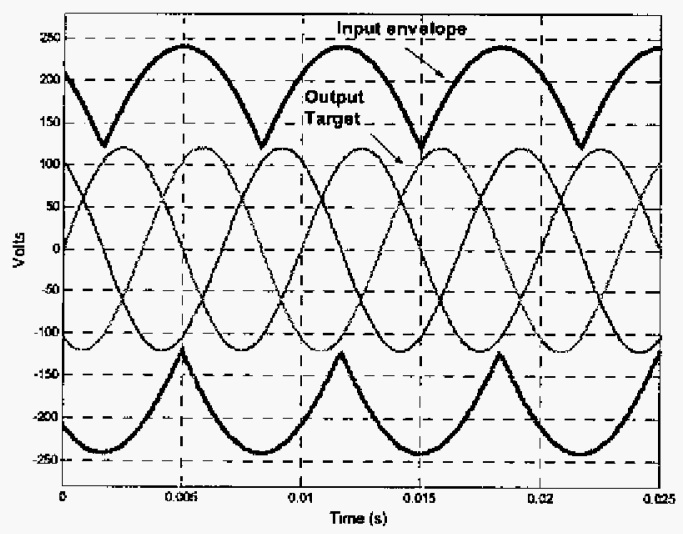

Figure 2.3: Illustrating maximum voltage ratio of $50 \%$.

\section{B. Venturini Modulation Method}

The first method attributable to Venturini [13] is defined by (4). However, calculating the switch timings directly from these equations is cumbersome for a practical implementation. They are more conveniently expressed directly in terns of the input voltages and the target output voltages (assuming unity displacement factor) in the form of :

$$
\begin{aligned}
& m_{g J}=\frac{t_{K V}}{T_{\text {seq }}}=\frac{1}{3}\left[1+\frac{2 V_{K} v_{j}}{V^{2}{ }_{i m t}}\right] \\
& \text { for } K=A, B, C \text { and } \mathrm{j}=a, b, c .
\end{aligned}
$$

This method is of little practical significance because of the $50 \%$ voltage ratio limitation imposed on the project. But for a three phase to single phase converter the above modulation is used since the other modulations require a 3 phase to 3 phase converter.

\section{BIRECTIONAL SWITCH \& CURRENT COMMUTATION}

The matrix converter requires a bidirectional switch capable of blocking voltage and conducting current in both directions. Unfortunately, there are no such devices currently avaitable, so discrete devices need to be used to construct suitable switch cells.

\section{A. Realization With Discrete Semiconductors}

There are four basic types of arrangements as shown in figure below.

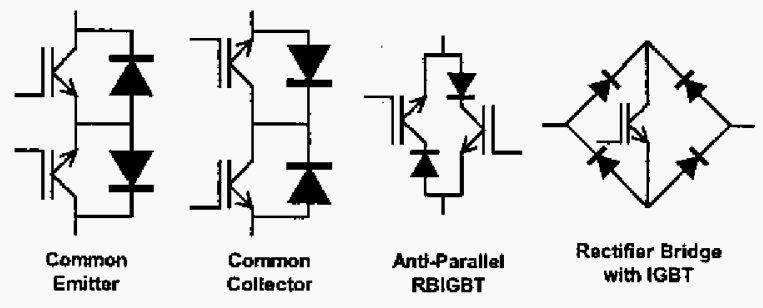

Figure 3. I: Bidirectional switch configurations.

The common emitter bidirectional switch cell arrangement consists of two diodes and two IGBTs connected in antiparallel as shown in Fig. 3.1. The diodes are included to provide the reverse blocking capability. There are several advantages in using this arrangement. The first is that it is possible to independently control the direction of the current. On the other hand, a disadvantage is that each bidirectional switch cell requires an isolated power supply for the gate drives.

Both the common collector and common emitter configurations can be used without the central connection but this connection does provide some transients during switching. In the common emitter configuration connection also allows both devices to be controlled by one isolated gate drive power supply.

\section{B. Current Commutation}

Reliable current commutation between switches in matrix converters is more difficult to achieve than in conventional VSIs since there are no natural freewheeling paths. The commutation has to be actively controlled at all times with respect to two basic rules. These rules can be visualized by considering just two switch cells on one output phase of a matrix converter. It is important that no two-bidirectional switches are switched on at any instant, as shown pictorially in Fig. 3,2(a). This would result in line-to-line short circuits and the destruction of the converter due to over currents. Also, the bidirectional switches for each output phase should not all be tumed off at any instant, as shown in Fig. 3.2(b). This would result in the absence of a path for the inductive load current, causing large over voltages. These two considerations 
cause a conflict since semiconductor devices cannot be switched instantaneously due to propagation delays and finite switching times.

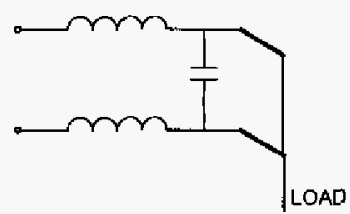

(a)

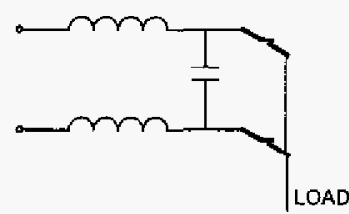

(b)
Figure 3.2: (a) Avoid short circuits on the matrix converter input lines. (b) Avoid open circuits on the matrix converter output lines.

\section{Current-Direction-Based Commutation}

A more reliable method of current commutation, which obeys the rules, uses a four-step commutation strategy in which the direction of current flow through the commutation cells can be controlled. To implement this strategy, the bidirectional switch cell must be designed in such a way as to allow the direction of the current flow in each switch cell to be controlled.

Fig. 3.3 shows a schematic of a two-phase to single-phase matrix converter, representing the first two switches in the converter. In steady state, both of the devices in the active bidirectional switch cell are gated to allow both directions of current flow. The following explanation assumes that the load current is in the direction shown and that the upper bidirectional switch $\left(S_{A d}\right)$ is closed.

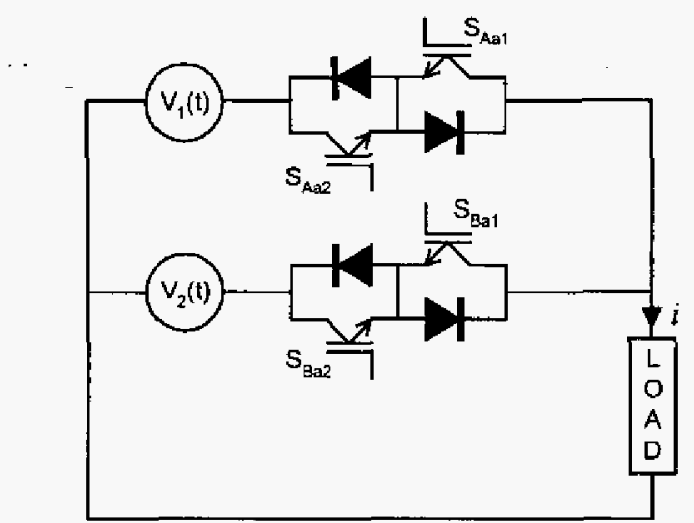

Figure 3.3: Two-phase to single-phase matrix converter.

When a commutation to $S_{B a}$ is required, the current direction is used to determine which device in the active switch is not conducting. This device is then turned off. In this case, device $S_{A a l}$ is turned off. The device that will conduct the current in the incoming switch is then gated,
$S_{B u 2}$ in this example. The load current transfers to the incoming device either at this point or when the outgoing device $\left(S_{A a z}\right)$ is tumed off. The remaining device in the incoming switch $\left(S_{B a I}\right)$ is turned on to allow current reversals. This process is shown as a timing diagram in Fig. 3.4; the delay between each switching even is determined by the device characteristics.

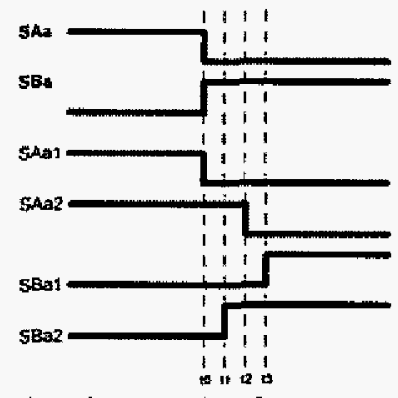

Figure 3.4: Four Step semi-soft current commutation between two bidirectional switch cells.

This method allows the current to commutate from one switch cell to another without causing a line-to-line short circuit or a load open circuit. One advantage of all these techniques is that the switching losses in the silicon devices are reduced by $50 \%$ because half of the commutation process is soft switching and, hence, this method is often called "semi-soft current commutation". One popular variation on this current commutation concept is to only gate the conducting device in the active switch cell, which creates a two-step current commutation strategy.

\section{DESIGN AND CONSTRUCTION}

The system consists of a three-phase source that feeds an input filter, which is made up of an inductor and a capacitor. This feeds the semiconductor switches that are driven by gate drive circuitry and controlled by a microcontroller board. Finally a single-phase load is connected. A block diagram of the system is shown in figure 4.1 .

The input filter design has to reduce the input current ripple with minimum installed energy on the reactive elements. The most used topology is an L-C series circuit. The input filter was designed so as to:

- produce an input filter with a cut-off frequency lower than the switching frequency

- maximize the displacement power factor $\cos (\varphi)$ for a given minimum output power $P_{\text {min }}$ 


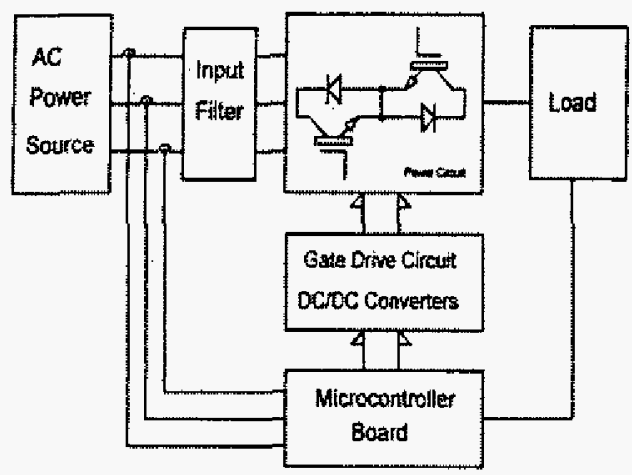

Figure 4.1: System block diagram.

Three low power $\mathrm{DC} / \mathrm{DC}$ converters were designed to provide threc-isolated $+15 \mathrm{~V}$ for each leg. Each isolated supply could switch two IGBTs since the emitters were connected together. Each $\mathrm{DC} / \mathrm{DC}$ converter consisted of a high frequency transformer.

Optocouplers were used to switch each IGBT. These provide isolation. The optocouplers used have an inbuilt push pull output that offers a maximum of $1.0 \mathrm{~V}$ low level output voltage, which eliminates the need for negative gate drive.

The microcontroller used was the PIC18F252 from Microchip. This is a Flash mictocontroller with 10-Bit A/D. It can handle up to $10 \mathrm{MIPs}$ (million instructions per second) when operated at $40 \mathrm{MHz}$ and has an internal $8 \mathrm{x}$ 8 single cycle hardware multiplier. This was very useful when a multiplication between two variables was required. It has $32 \mathrm{Kbytes}$ on-chip program memory, 1536 bytes on-chip RAM and 256 data EEPROM. It has 3 ports that can be configured as input and output. It has special pins that if configured, can perform a specific function such as the interrupts.

Instead of sensing the phase voltages $V_{A}, V_{B}$ and $V_{C}$; the line voltages $V_{A B}$ and $V_{B C}$ were sensed and by using a software algorithm, $V_{A}, V_{B}$ and $V_{C}$ were computed. These voltages were sensed using 2 voltage transducers; that provides isolation; and replicate the input waveform at the output side.

A watchdog circuit was designed to ensure that the microcontroller does not stop functioning, i.e. the microcontroller must continuously output a pulsating signal.

A low value resistor $(0.33 \Omega)$ in series with the load was used to sense the current direction of the load.
The clamp circuit is an important component for matrix converters. Under normal condition, the main use of this circuit is to provide a path for the commutation energy stored in the load (motor) leakage inductance. Under a faulted condition, all switches in the converter are immediately tumed off so that the clamp serves to deenergize the load current without damaging the power switches. Generally, the clamp circuit of a conventional matrix converter consists of dual six-pack diode rectifiers and one capacitor. But for a three-phase to single-phase converter only eight diodes were needed.

The appropriate value of capacitor depends on the load current, the load inductance, and the highest allowable capacitor voltage.

\section{RESULTS (EXPERIMENTAL)}

Experiments with two types of loads were carried out on the three phase to single phase $\mathrm{MC}$. The first test was carried out using a resistive load and the second test used an inductive load (single phase induction motor).

In both experiments, the voltage waveform applied to the load is shown in figure 5.1.

For the resistive load the current waveform was a scaled replica of the voltage waveform.

For the second experiment, a single-phase induction motor was used. The voltage, current and frequency waveforms obtained with an input voltage of $60 \mathrm{~V} 50 \mathrm{~Hz}$ and a demanded output frequency of $20 \mathrm{~Hz}$ are shown in figures $5.1,5.2$ and 5.3 respectively..

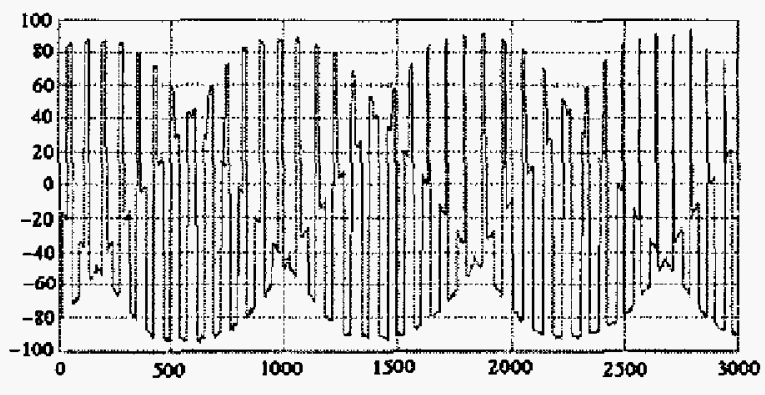

Figure 5.1: Output voltage waveform at $20 \mathrm{~Hz}$ with an input voltage of $60 \mathrm{~V}$. 


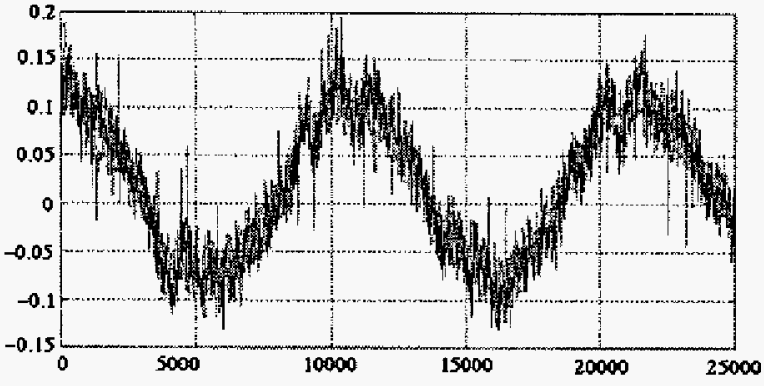

Figure 5.2: Current waveform with a single-phase induction motor manning at $20 \mathrm{~Hz}$.

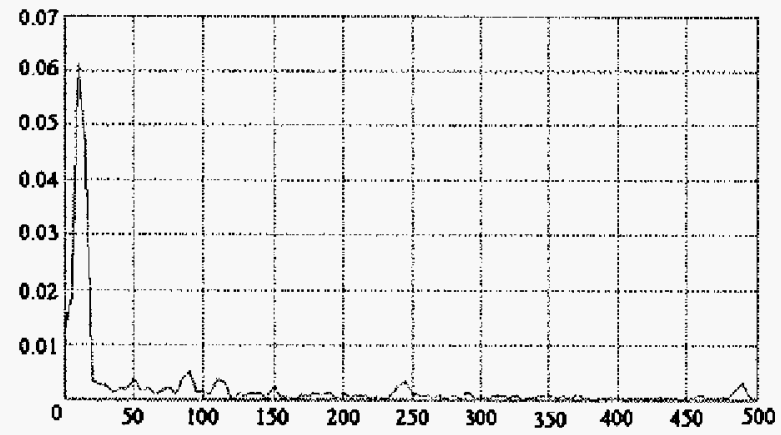

Figure 5.3: Frequency response of the current waveform (Main Component at 20Hz).

\section{CONCLUSIONS}

The results presented in Section $V$ show that the system designed and implemented in this project was successful. Direct ac-to-ac conversion was achieved using four step current commutation. For this type of converter a low-cost microcontroller is sufficient to implement the switching algorithm. However for a three-phase to three-phase converter two other microcontrollers would be required and they would have to be controlled via a main microcontroller. For a three phase output, the best implementation is using one powerful microprocessor, however the low cost microcontrollers good be used for the current commutation scheme allowing different schemes to be implemented relatively easily.

This specific type of ac to ac converter with a single output phase can find application in grid connected renewable energy sources. Using a matrix converter, would eliminate any internediate power electronic circuitry required for grid connection of a.c. sources. With an appropriate electrical drive control, the matrix converter can be used to connect a low power $(<20 \mathrm{~kW})$ three phase wind generator directly to the grid.

\section{REFERENCES}

[1] M. G. B. Venturini and A. Alesina, "Intrinsic amplitude limits and optimum design of 9-switches direct PWM-AC-AC Converters," in Proc. IEEE PESC.SS, 1998, pp. 1284-1291

[2] L. Huber and D. Borojevic, "Space vector modulated three-phase to three-phase matrix converter with input power factor correction," IEEE Trans. Ind. Applicat., vol. 31, pp. 1234-1246, Nov/Dec 1995.

[3] J. Oyama, X. Xia, T. Higuchi, and E. Varnada, "Displacement angle control of matrix converter," in Proc. IEEE PESC'97, 1997, pp. 1033-1039

[4] P. Nielsen, "The matrix converter for an induction motor drive," Ph.D. dissertation, Aalborg Univ.. Aalhorg East, Denmark, 1996.

[5] P. Nielsen, D Casadei, G. Serra, aod A. Tani, "Evaluation of the input current quality by three different modulation strategies for SYM controlled matrix converters with input voltage unbalance," in Proc PEDES'96, vol. 2, 1996, pp. 794-800.

[6] S. Bemet. T. Matsuo, and T. A Lipo, "A matrix converter using reverse blocking NPT-IGBT's and optimized pulse patterns," in Proc IEEE PESC' 96 , Baveno, Italy, 1996, pp. 107-113

[7] M. Homkamp, M. Loddenkoetter, M. Muenzer, O. Simon, and M Bruckmann, "EconoMAC the first all-in-one IGBT module for matrix converters," in Proc PCIM,2001.

[8] C. Klumpner, $F$ Blaabjerg, and $P$ Nielsen, "Speeding-up the maturation process of the matrix converter technology," in Proc IEEE PESC, vol 2,2001, pp. 1083-1088.

[9] M. Ziegler and W Hoffmann, "Semi-natural two steps commutation strategy," in Proc IEEE PESC98, 1998, pp. 727-731.

[10] R. J. Kerkman, G. 1. Skibinski, and D. W. Schlegel, "AC drives: Year 2000 (Y2K) and beyond," in Proc. IEEE APEC'99, vol, I, 1999, pp. 28-39. .

[11] P. Thogersen, P. Nielsen, and F. Abrahamsen, "Impacts on energy savings by variable speed drives from motor and converter technology," in Proc. PCIM'99, Intelligent Motion, 1999, pp. 1-7.

[12] F. Abrahamsen, F. Blaabjerg, J. K. Pedersen, P. Grabowski, and $P$. Thogersen, "On the energy optimized control of standard and high-efficiency induction motors in CT and HVAC applications," IEEE Trans. Ind. Applicat., vol. 34,pp. 822-831, July/Aug. 1998. 